\title{
On the Volatility of Daily Stock Returns of Total Petroleum Company of Nigeria: Evidence from GARCH Models, Value-at-Risk and Backtesting
}

\author{
${ }^{1}$ Emenogu, G. Ngozi; ${ }^{2 *}$ Adenomon, M. O. \& ${ }^{2}$ Nweze, N. O. \\ 1. Department of Statistics, Federal Polytechnic, Bida, Niger State, Nigeria \\ 2. Department of Statistics, Nasarawa State University, Keffi, Nasarawa State, Nigeria \\ * Corresponding Authors: adenomonmo@nsuk.edu.ng; ngelive4jesus@ gmail.com; \\ obininweze@yahoo.com +2347036990145; +2348036759112
}

\begin{abstract}
Total Nigeria Plc is a Marketing and Services subsidiary of Total; a multinational energy company operating in more than 130 countries and committed to providing sustainable products and services for its customers. For over 50 years, Total Nigeria Plc has remained the leader in the downstream sector of the Nigerian oil and gas industry. This study investigated the volatility of the stock price of Total Petroleum Nigeria plc using nine (9) GARCH models namely sGARCH, gjrGARCH, eGARCH, iGARCH, aPARCH, TGARCH, NGARCH, NAGARCH and AVGARCH. We also investigated the Value-at-Risk (VaR) and Backtesting of the Models. The aim actually of this study is to boost the confidence of the shareholders and investors of the Total Nigeria plc. To achieve this, daily stock price for Total petroleum Nigeria plc from secondary was collected from January $2^{\text {nd }} 2001$ to May $8^{\text {th }} 2017$. . The study used both normal and student $t$ innovations, using Akaike Information Criterion (AIC) to select the best model, for normal innovations for log returns and cleansed log returns of Total plc, the eGARCH and sGARCH models performed best respectively, while NGARCH model performed best for student $t$ innovation for both log returns and cleansed returns of Total plc. The persistence of the models are stable except in few cases where iGARCH, eGARCH where not stable. Also for student $t$ innovation, the sGARCH and gjrGARCH fails to converge. The mean-reverting number of day for the returns of Total Nigeria plc differs from model to model. Evidence from the VaR Analysis revealed from the selected models revealed that the Risk of VaR losses is high at $99 \%$ confidence level, slightly high at $95 \%$ confidence level and better at $90 \%$ confidence level. Although The Duration-Based Tests of independence conducted revealed that the models are correctly specified since in all cases the null hypotheses were accepted. This means that the probability of an exception on any day did not depends on the outcome of the previous day. Finally, both the unconditional (Kupiec) and conditional (Christoffersen) coverage tests for the correct number of exceedances for both Total stock returns and cleansed returns. The tests revealed rejection of the models at $1 \%$ level of significance. This confirms that unconditional (Kupiec) and conditional (Christoffersen) coverage tests for the correct number of exceedances are reliable compared to the Duration-Based Tests of independence. Therefore we recommend that shareholders and investors in Total Nigeria plc are to remain and continue to investment in Total Nigeria plc because if there is any form of losses, the price of the stock has the potentials to improve in the future. Again, though the risk is high at $99 \%$ confidence level, this in line with the financial theory that states that an asset with high expected risk would pay higher return on the average.
\end{abstract}

Keywords: Volatility, Returns, Stocks, Total Petroleum, Akaike Information Criterion (AIC), GARCH, Value-at-Risk (VaR), Backtesting. 


\subsection{Introduction}

Financial theory states that an asset with high expected risk would pay higher return on the average (Xekalaki and Degiannakis, 2010). This relationship between investors' expected return and risk was measeared and represented by Engle et al. (1987) using the Auto-Regressive Conditional Heteroscedasticity (ARCH) given as

$$
\left.\begin{array}{l}
y_{t}=x_{t}^{\prime} \beta+\varphi\left(\sigma_{t}^{2}\right)+\varepsilon_{t} \\
\varepsilon_{t} \mid I_{t-1} \sim f\left(0, \sigma_{t}^{2}\right), \\
\sigma_{t}^{2}=g\left(\sigma_{t-1}, \sigma_{t-2}, \ldots ; \varepsilon_{t-1}, \varepsilon_{t-2}, \ldots ; v_{t-1}, v_{t-2}, \ldots\right)
\end{array}\right\}
$$

where $x_{t}$ is a $\mathrm{kx} 1$ vector of endogeneous and exogeneous explanatory variables included in the set $I_{t-1}$ and $\varphi\left(\sigma_{t}^{2}\right)$ represents the risk premium, which means increase in the rate of return due to an increase in the variables of the returns.

From the economist point of view, resources are scare in the world especially in developing countries of which Nigeria belong (Maxwell and Reuveny, (2000) \& IPI, (2009)). According to Mildner et al. (2011), resources scarcity is increasingly perceived as one of the greatest security risk of the twenty-first century. This situation in developing countries has made investors to paly safe in investment uncertainty. Ahmadi et al. (2018) identified three characteristics of investment decision as Cost of investment, uncertainty over future profits and seeking for additional information to reduce uncertainty. These and many more are provided by stock brokers, accountants, financial analyst and financial econometricians and financial time series analysts. The most dependable is the financial econometricians and financial time series analysts due to volatility and value at risk presents in stock prices.

Financial econometrics and financial time series analysis provides the following: better understanding on how prices behave and knowledge of price behavior to reduce risk or enhances better decision (Aas \& Dimakos, 2004). This is done using time series models for forecasting, option pricing and risk management.

Nigeria as a country that depended more on oil (Adenomon, 2016) and a major player in the oil market (Ahmadi et al., 2018), investors in Nigeria have invested and are still investing in stock of oil company such as Total Petroleum Company of Nigeria.

Total Nigeria Plc is a Marketing and Services subsidiary of Total; a multinational energy company operating in more than 130 countries and committed to providing sustainable products 
and services for its customers. For over 50 years, Total Nigeria Plc has remained the leader in the downstream sector of the Nigerian oil and gas industry with an extensive distribution network of over 500 service stations nationwide and a wide range of top quality energy products and services. TOTAL NIGERIA PLC (RC 1396) was incorporated as a private company on June 1, 1956 to market petroleum products in Nigeria. In September 11, 2001, the company had a successful merger which paved way for sustainable growth and continuous development. The share capital of the company after the merger is presently $\$ 169,761,000$ made up of 50k ordinary shares authorized and fully paid up with Nigerian Citizens and Associations holding $38.28 \%$ of the share capital (http://www.total.com.ng/pro/about-us.html).

Total share price is very high ( 199.10 as at 16-11-2018 (https//www.bloomberg.com/quote/TOTAL:NL)) and as such the risk and returns would also be high. The investors in this company and sector needed information to reduce their risk and to enhance their investment decisions.

This study investigates the volatility and the Value at Risk (VaR) of daily stock of total petroleum company Nigeria in order to boost the confidence of her shareholders and investors.

\subsection{Review of Literature on Volatility and VaR of stocks of oil company and in oil markets}

Volatility is a statistical measure of the dispersion of returns for a given security or market index. One can measure volatility using the standard deviation or variance between returns from the same security or market index but the higher the volatility, the riskier the security. That is why crude oil prices and its stock prices fluctuate heavily and are become more volatile (Ulusoy \& Ozdurak, 2018).

On the other hand, Value at Risk (VaR) is a statistical measure of the riskiness of financial entities or portfolio of assets (Corkalo, 2011). In addition, it is define as the maximum a given amount of currency or price of stock is expected to be lost over a given time horizon, at a pre-defined confidence level (Best, (1998); Bali \& Cakici, (2004)).

Previous studies are as follows: Bali and Cakici (2004) stated that stock size, liquidity and Value at Risk (VaR) can explain the cross-sectional variation in expected returns than Beta and total volatility and concluded that relationship between average returns and $\mathrm{VaR}$ is robust for different investment horizons and loss probability level while VaR has additional explanatory power for stock returns. 
Corkalo (2011) compared the main approaches of calculating VaR and implements variance-covariance, historical simulation and bootstrapping approach on stock portfolio and presented results using histogram. Corkalo recommended that investor or risk manager must look at composition of its portfolio and then choose appropriate method to calculate VaR. a similar work was done by van den Goorbergh and Vlaar (1999).

Asaolu and Ilo (2012) investigated the relationship between the Nigerian stock market and world crude oil price. The study showed that the Nigerian stock market and oil price are tied to gather in the long run as anticipated given the dominance of oil sector on the Nigerian economy.

Ogiri et al. (2013) studied oil price and stock market performance in Nigeria using VECM and VAR model. Their result revealed oil price changes are important factors in explaining stock price movement in Nigeria.

Akinlo (2014) examined the relationship between oil price and stock market in Nigeria using the Vector Error Correction Model approach. The study revealed that oil price, exchange rate and stock market development are cointegrated while oil price has a temporary positive impact on stock market growth in Nigeria.

Alley et al. (2014) investigated the effect of oil price shocks on the Nigerian economy using annual data from 1981 to 2012 and employed the General methods of moment (GMM) in the analysis of the data. They found that the oil price shocks insignificantly retard the economic growth while oil prices itself significantly improve the economic growth.

Akinlo and Apanisile (2015) examined the impact of the volatility of oil price on economic growth in 20 Sub-Saharan African countries from 1986-2012. The panel pooled OLS was employed and the results revealed that the volatility of oil has a positive and significant effect on the economic growth of the oil exporting countries while for non-oil exporting countries the volatility of the oil price has a positive and insignificant impact on the economic growth.

Abdulkareem and Abdulkareem (2016) analyzed macroeconomic variables and oil price volatility in Nigeria using GARCH model and its variants employing daily, monthly and quarterly data sets. The study concluded that oil price is a major source of macroeconomic volatility in Nigeria. 
Odupitan (2017) found out that because of the global prices of crude oil crashed in 2014, government revenues also declined while the non-oil sector also contracted as a result. This resulted to negative effects on the Nigerian economy as she suffered from job loss, stagnated savings, increased external debt. Odupitan suggested that for the country to overcome all these challenges, diversification of the economy should be considered and implemented by the Nigerian government.

Jarrett et al. (2017) investigated the impact of local financial development and openness measures on mitigating oil volatility from data set of 194 countries between 1980 and 2014 with the application of ARDL model. They found out that financial measures do mitigate the effects of oil price volatility in the introduction of these measures can reduced or completely eliminate the negative effects of oil volatility on growth.

Okere and Ndubuisi (2017) investigated the relationship between crude oil price and stock market development and economic growth in Nigeria over 1981 to 2014 using ARDL model. The study concluded that the dominant role of oil price is one of the engines that drive economic growth in Nigeria.

Ahmadi et al. (2018) studied investment and uncertainty relationship in the oil and gas industry of U.S using SVAR-GARCH model. Their result revealed that oil market uncertainty lower investment only when it is caused by global consumption demand shocks while market uncertainty is found to have a negative effect on investment with a year of delay.

Okoye et al. (2018) empirically examined the interrelationship between the construction sector, oil prices and Gross domestic product (GDP) in Nigeria and they found that there exist short run linear relationships among these macroeconomic variables. They argued that neither construction sector nor oil prices directly influences the aggregate economy.

\subsection{Model Specification}

This study focuses on the GARCH models that are robust for forecasting the volatility of financial time series data; so GARCH model and some of its extensions are presented in this section

\subsection{Autoregressive Conditional Heteroskedasticity (ARCH) Family Model}

Every ARCH or GARCH family model requires two distinct specifications, namely: the mean and the variance equations (Atoi, 2014). The mean equation for a conditional heteroskedasticity in a return series, $y_{t}$ is given by 


$$
y_{t}=E_{t-1}\left(y_{t}\right)+\varepsilon_{t}
$$

where

$$
\varepsilon_{t}=\phi_{t} \sigma_{t}
$$

The mean equation in equation (2) also applies to other GARCH family models. $E_{t-1}($.$) is the$ expected value conditional on information available at time $t$ - 1 , while $\varepsilon_{t}$ is the error generated from the mean equation at time $\mathrm{t}$ and $\phi_{t}$ is the sequence of independent and identically distributed random variables with zero mean and unit variance.

The variance equation for an $\mathrm{ARCH}(\mathrm{p})$ model is given by

$$
\sigma_{t}^{2}=\omega+\alpha_{1} a_{t-1}^{2}+\ldots+\alpha_{p} a_{t-p}^{2}
$$

It can be seen in the equation that large values of the innovation of asset returns have bigger impact on the conditional variance because they are squared, which means that a large shock tends to follow another large shock and that is the same way the clusters of the volatility behave. So the ARCH(p) model becomes:

$$
a_{t}=\sigma_{t} \varepsilon_{t}, \quad \sigma_{t}^{2}=\omega+\alpha_{1} a_{t-1}^{2}+\ldots+\alpha_{p} a_{t-p}^{2}
$$

Where $\varepsilon_{t} \sim N(0,1)$ iid, $\omega>0$ and $\alpha_{i} \geq 0$ for $i>0$. In practice, $\varepsilon_{t}$ is assumed to follow the standard normal or a standardized student $t$ distribution or a generalized error distribution (Tsay 2005).

\subsection{Asymmetric Power ARCH}

According to Rossi (2004), the asymmetric power ARCH model proposed by Ding, Engle \& Granger (1993) given below forms the basis for deriving the GARCH family models

Given that:

$$
\begin{gathered}
r=\mu+a_{t}, \\
\varepsilon_{t}=\sigma_{t} \varepsilon_{t}, \\
\varepsilon_{t} \sim N(0,1) \\
\sigma_{t}^{\delta}=\omega+\sum_{i=1}^{p} \alpha_{i}\left(\left|a_{t-i}\right|-\gamma_{i} a_{t-i}\right)^{\delta}+\sum_{j=1}^{q} \beta_{j} \sigma_{t-j}^{\delta},
\end{gathered}
$$

where

$$
\begin{array}{ll}
\omega>0, & \delta \geq 0, \\
\alpha_{i} \geq 0 & i=1,2, \ldots, p
\end{array}
$$




$$
\begin{array}{ll}
-1<\gamma_{i}<1 & i=1,2, \ldots, p \\
\beta_{j}>0 & j=1,2, \ldots, q
\end{array}
$$

This model imposes a Box-Cox transformation of the conditional standard deviation process and the asymmetric absolute residuals. The leverage effect is the asymmetric response of volatility to positive and negative "shocks".

\subsection{Standard GARCH(p, q) Model:}

The mathematical model for the $\operatorname{sGARCH}(\mathrm{p}, \mathrm{q})$ model is obtained from equation (5) by letting $\delta=2$ and $\gamma_{i}=0, i=1, \ldots, p$ to be:

$$
a_{t}=\sigma_{t} \varepsilon_{t}, \quad \sigma_{t}^{2}=\omega+\sum_{i=1}^{p} \alpha_{i} a_{t-i}^{2}+\sum_{j=1}^{q} \beta_{j} \sigma_{t-j}^{2}
$$

Where $a_{t}=r_{t}-\mu_{t}\left(r_{t}\right.$ is the continuously compounded log return series), and $\varepsilon_{t} \sim N(0,1)$ iid, the parameter $\alpha_{i}$ is the $\mathrm{ARCH}$ parameter and $\beta_{j}$ is the $\mathrm{GARCH}$ parameter, and $\omega>0, \alpha_{i} \geq 0, \beta_{j} \geq 0$, and $\sum_{i=1}^{\max (p, q)}\left(\alpha_{i}+\beta_{i}\right)<1$, (Rossi, 2004; Tsay, 2005 and Jiang, 2012).

The restriction on $\mathrm{ARCH}$ and GARCH parameters $\left(\alpha_{i}, \beta_{j}\right)$ suggests that the volatility $\left(a_{i}\right)$ is finite and that the conditional standard deviation $\left(\sigma_{i}\right)$ increases. It can be observed that if $\mathrm{q}=0$, then the model GARCH parameter $\left(\beta_{j}\right)$ becomes extinct and what is left is an $\mathrm{ARCH}(\mathrm{p})$ model. To expatiate on the properties of GARCH models, the following representation is necessary: Let $\eta_{t}=a_{t}^{2}-\sigma_{t}^{2}$ so that $\sigma_{t}^{2}=a_{t}^{2}-\eta_{t}$. By substituting $\sigma_{t-i}^{2}=a_{t-i}^{2}-\eta_{t-i},(i=0, \ldots, q)$ into Eq. (4), the GARCH model can be rewritten as

$$
a_{t}=\alpha_{0}+\sum_{i=1}^{\max (p, q)}\left(\alpha_{i}+\beta_{i}\right) a_{t-i}^{2}+\eta_{t}-\sum_{j=1}^{q} \beta_{j} \eta_{t-j},
$$

It can be seen that $\left\{\eta_{t}\right\}$ is a martingale difference series (i.e., $E\left(\eta_{t}\right)=0$ and $\operatorname{cov}\left(\eta_{t}, \eta_{t-j}\right)=0$, for $\left.j \geq 1\right)$. However, $\left\{\eta_{t}\right\}$ in general is not an iid sequence.

A GARCH model can be regarded as an application of the ARMA idea to the squared series $a_{t}^{2}$. Using the unconditional mean of an ARMA model, results in this

$$
\mathrm{E}\left(a_{t}^{2}\right)=\frac{\alpha_{0}}{1-\sum_{i=1}^{\max (p, q)}\left(\alpha_{i}+\beta_{i}\right)}
$$


provided that the denominator of the prior fraction is positive. (Tsay, 2005)

When $\mathrm{p}=1$ and $\mathrm{q}=1$, we have $\operatorname{GARCH}(1,1)$ model given by:

$$
\begin{aligned}
& a_{t}=\sigma_{t} \varepsilon_{t}, \\
& \sigma_{t}^{2}=\omega+\alpha_{1} a_{t-1}^{2}+\beta_{1} \sigma_{t-1}^{2},
\end{aligned}
$$

\subsection{GJR-GARCH(p, q) Model}

The Glosten-Jagannathan-Runkle GARCH (GJRGARCH) model, which is a model that attempts to address volatility clustering in an innovation process, is obtained by letting $\delta=2$.

When $\delta=2$ and $0 \leq \gamma_{i}<1$,

$$
\begin{aligned}
& \sigma_{t}^{2}=\omega+\sum_{i=1}^{p} \alpha_{i}\left(\left|\varepsilon_{t-i}\right|-\gamma_{i} \varepsilon_{t-i}\right)^{2}+\sum_{j=1}^{q} \beta_{j} \sigma_{t-j}^{2} \\
& =\omega+\sum_{i=1}^{p} \alpha_{i}\left(\left|\varepsilon_{t-i}\right|^{2}+\gamma_{i}^{2} \varepsilon_{t-1}^{2}-2 \gamma_{i}\left|\varepsilon_{t-i}\right| \varepsilon_{t-i}\right)+\sum_{j=1}^{q} \beta_{j} \sigma_{t-j}^{2} \\
& \sigma_{t}^{2}= \begin{cases}\omega+\sum_{i=1}^{p} \alpha_{i}^{2}\left(1+\gamma_{i}\right)^{2} \varepsilon_{t-i}^{2}+\sum_{j=1}^{q} \beta_{j} \sigma_{t-j}^{2}, & \varepsilon_{t-i}<0 \\
\omega+\sum_{i=1}^{p} \alpha_{i}\left(1-\gamma_{i}\right)^{2} \varepsilon_{t-i}^{2}+\sum_{j=1}^{q} \beta_{j} \sigma_{t-j}^{2}, & \varepsilon_{t-i}>0\end{cases}
\end{aligned}
$$

i.e; $\quad \sigma_{t}^{2}=\omega+\sum_{i=1}^{p} \alpha_{i}\left(1-\gamma_{i}\right)^{2} \varepsilon_{t-i}^{2}+\sum_{i=1}^{p} \alpha_{i}\left\{\left(1+\gamma_{i}\right)^{2}-\left(1-\gamma_{i}\right)^{2}\right\} S_{i}^{-} \varepsilon_{t-i}^{2}+\sum_{j=1}^{q} \beta_{j} \sigma_{t-j}^{2}$

$$
\sigma_{t}^{2}=\omega+\sum_{i=1}^{p} \alpha_{i}\left(1-\gamma_{i}\right)^{2} \varepsilon_{t-1}^{2}+\sum_{j=1}^{q} \beta_{j} \sigma_{t-1}^{2}+\sum_{i=1}^{p} 4 \alpha_{i} \gamma_{i} S_{i}^{-} \varepsilon_{t-i}^{2}
$$

where

$$
S_{i}^{-}=\left\{\begin{array}{l}
1 \text { if } \varepsilon_{t-i}<0 \\
0 \text { if } \varepsilon_{t-i} \geq 0
\end{array}\right.
$$

Now define

$$
\alpha_{i}^{*}=\alpha_{i}\left(1-\gamma_{i}\right)^{2} \text { and } \gamma_{i}^{*}=4 \alpha_{i} \gamma_{i}
$$

then

$$
\sigma_{t}^{2}=\omega+\sum_{i=1}^{p} \alpha_{i}\left(1-\gamma_{i}\right)^{2} \varepsilon_{t-i}^{2}+\sum_{j=1}^{q} \beta_{j} \sigma_{t-i}^{2}+\sum_{i=1}^{p} \gamma_{i}^{*} S_{i}^{-} \varepsilon_{t-1}^{2}
$$

Which is the GJRGARCH model (Rossi, 2004).

But when $-1 \leq \gamma_{i}<0$, 
Then recall Eq. (9)

$$
\begin{aligned}
& \sigma_{t}^{2}=\omega+\sum_{i=1}^{p} \alpha_{i}\left(\left|\varepsilon_{t-i}\right|-\gamma_{i} \varepsilon_{t-i}\right)^{2}+\sum_{j=1}^{q} \beta_{j} \sigma_{t-j}^{2} \\
& =\omega+\sum_{i=1}^{p} \alpha_{i}\left(\left|\varepsilon_{t-i}\right|^{2}+\gamma_{i}^{2} \varepsilon_{t-1}^{2}-2 \gamma_{i}\left|\varepsilon_{t-i}\right| \varepsilon_{t-i}\right)+\sum_{j=1}^{q} \beta_{j} \sigma_{t-j}^{2} \\
& \sigma_{t}^{2}= \begin{cases}\omega+\sum_{i=1}^{p} \alpha_{i}^{2}\left(1-\gamma_{i}\right)^{2} \varepsilon_{t-i}^{2}+\sum_{j=1}^{q} \beta_{j} \sigma_{t-j}^{2}, & \varepsilon_{t-i}>0 \\
\omega+\sum_{i=1}^{p} \alpha_{i}\left(1+\gamma_{i}\right)^{2} \varepsilon_{t-i}^{2}+\sum_{j=1}^{q} \beta_{j} \sigma_{t-j}^{2}, & \varepsilon_{t-i}<0\end{cases} \\
& \sigma_{t}^{2}=\omega+\sum_{i=1}^{p} \alpha_{i}\left(1+\gamma_{i}\right)^{2} \varepsilon_{t-i}^{2}+\sum_{j=1}^{q} \beta_{j} \sigma_{t-j}^{2}+\sum_{i=1}^{p} \alpha_{i}\left\{\left(1-\gamma_{i}\right)^{2}-\left(1+\gamma_{i}\right)^{2}\right\} S_{i}^{+} \varepsilon_{t-i}^{2} \\
& =\omega+\sum_{i=1}^{p} \alpha_{i}\left(1+\gamma_{i}\right)^{2} \varepsilon_{t-i}^{2}+\sum_{j=1}^{q} \beta_{j} \sigma_{t-j}^{2}+\sum_{i=1}^{p} \alpha_{i}\left\{1+\gamma_{i}^{2}-2 \gamma_{i}-1-\gamma_{i}^{2}-2 \gamma_{i}\right\} S_{i}^{+} \varepsilon_{t-i}^{2}
\end{aligned}
$$

Where

$$
S_{i}^{+}=\left\{\begin{array}{l}
1 \text { if } \varepsilon_{t-i}>0 \\
0 \text { if } \varepsilon_{t-i} \leq 0
\end{array}\right.
$$

also define

$$
\alpha_{i}^{*}=\alpha_{i}\left(1+\gamma_{i}\right)^{2} \text { and } \gamma_{i}^{*}=-4 \alpha_{i} \gamma_{i}
$$

then

$$
\sigma_{t}^{2}=\omega+\sum_{i=1}^{p} \alpha_{i}^{*} \varepsilon_{t-i}^{2}+\sum_{j=1}^{q} \beta_{j} \sigma_{t-i}^{2}+\sum_{i=1}^{p} \gamma_{i}^{*} S_{i}^{+} \varepsilon_{t-1}^{2}
$$

which allows positive shocks to have a stronger effect on volatility than negative shocks (Rossi, 2004). But when $p=q=1$, the GJRGARCH(1,1) model will be written as

$$
\sigma_{t}^{2}=\omega+\alpha \varepsilon_{t}^{2}+\gamma S_{i} \varepsilon_{t-1}^{2}+\beta \sigma_{t-1}^{2} .
$$

\subsection{IGARCH(1, 1) Model}

The integrated GARCH (IGARCH) models are unit- root GARCH models. The IGARCH $(1,1)$ model is specified in Tsay (2005) and Grek (2014) as

$$
a_{t}=\sigma_{t} \varepsilon_{t} ; \quad \sigma_{t}^{2}=\alpha_{0}+\beta_{1} \sigma_{t-1}^{2}+\left(1-\beta_{1}\right) a_{t-1}^{2}
$$

Where $\varepsilon_{t} \sim \mathrm{N}(0,1)$ iid, and $0<\beta_{1}<1$, Ali (2013) used $\alpha_{i}$ to denote $1-\beta_{i}$. 
The model is also an exponential smoothing model for the $\left\{a_{t}^{2}\right\}$ series. To see this, rewrite the model as

$$
\begin{aligned}
\sigma_{t}^{2} & =\left(1-\beta_{1}\right) a_{t-1}^{2}+\beta_{1} \sigma_{t-1}^{2} \\
& =\left(1-\beta_{1}\right) a_{t-1}^{2}+\beta_{1}\left[(1-\beta) a_{t-2}^{2}+\beta_{1} \sigma_{t-2}^{2}\right] \\
& =\left(1-\beta_{1}\right) a_{t-1}^{2}+\left(1-\beta_{1}\right) \beta_{1} a_{t-2}^{2}+\beta_{1}^{2} \sigma_{t-2}^{2} .
\end{aligned}
$$

By repeated substitutions, we have

$$
\sigma_{t}^{2}=\left(1-\beta_{1}\right)\left(a_{t-1}^{2}+\beta_{1} a_{t-2}^{2}+\beta_{1}^{2} a_{t-3}^{3}+\cdots\right),
$$

which is the well-known exponential smoothing formation with $\beta_{1}$ being the discounting factor (Tsay, 2005).

\subsection{TGARCH(p, q) Model}

The Threshold GARCH model is another model used to handle leverage effects, and a $\operatorname{TGARCH}(\mathrm{p}, \mathrm{q})$ model is given by the following:

$$
\sigma_{t}^{2}=\alpha_{0}+\sum_{i=1}^{p}\left(\alpha_{i}+\gamma_{i} N_{t=i}\right) a_{t-i}^{2}+\sum_{j=1}^{q} \beta_{j} \sigma_{t-j}^{2},
$$

where $N_{t-i}$ is an indicator for negative $a_{t-i}$, that is,

$$
N_{t-i}=\left\{\begin{array}{l}
1 \text { if } a_{t-i}<0 \\
0 \text { if } a_{t-i} \geq 0
\end{array}\right.
$$

and $\alpha_{i}, \gamma_{i}$, and $\beta_{j}$ are nonnegative parameters satisfying conditions similar to those of GARCH models, (Tsay, 2005). When $p=1, q=1$, the TGARCH(1,1) model becomes:

$$
\sigma_{t}^{2}=\omega+\left(\alpha+\not N_{t-1}\right) a_{t-1}^{2}+\beta \sigma_{t-1}^{2}
$$

\subsection{NGARCH(p, q) Model}

The Nonlinear Generalized Autoregressive Conditional Heteroskedasticity (NGARCH) Model has been presented variously in literature by the following scholars: Hsieh \& Ritchken (2005), Lanne \& Saikkonen (2005), Malecka (2014) and Kononovicius \& Ruseckas (2015). The following model can be shown to represent all the presentations:

$$
h_{t}=\omega+\sum_{i=1}^{q} \alpha_{i} \varepsilon_{t-i}^{2}+\sum_{i=1}^{q} \gamma_{i} \varepsilon_{t-i}+\sum_{j=1}^{p} \beta_{j} h_{t-j}
$$

Where $h_{t}$ is the conditional variance, and $\omega, \beta$ and $\alpha$ satisfy $\omega>0, \beta \geq 0$ and $\alpha \geq 0$. 
Which can also be written as

$$
\sigma_{t}=\omega+\sum_{i=1}^{q} \alpha_{i} \varepsilon_{t-i}^{2}+\sum_{i=1}^{q} \gamma_{i} \varepsilon_{t-i}+\sum_{j=1}^{p} \beta_{j} \sigma_{t-j}
$$

\subsection{The Exponential Generalized Autoregressive Conditional Heteroskedasticity}

\section{(EGARCH) Model}

The EGARCH model was proposed by Nelson (1991) to overcome some weaknesses of the GARCH model in handling financial time series pointed out by Enocksson and Skoog(2012), In particular, to allow for asymmetric effects between positive and negative asset returns, he considered the weighted innovation

$$
g\left(\varepsilon_{t}\right)=\theta \varepsilon_{t}+\gamma\left[\left|\varepsilon_{t}\right|-E\left(\left|\varepsilon_{t}\right|\right)\right]
$$

where $\theta$ and $\gamma$ are real constants. Both $\varepsilon_{t}$ and $\left|\varepsilon_{t}\right|-E\left(\left|\varepsilon_{t}\right|\right)$ are zero-mean iid sequences with continuous distributions. Therefore, $E\left[g\left(\varepsilon_{t}\right)\right]=0$. The asymmetry of $g\left(\varepsilon_{t}\right)$ can easily be seen by rewriting it as

$$
g\left(\varepsilon_{t}\right)=\left\{\begin{array}{l}
(\theta+\gamma) \varepsilon_{t}-\gamma E\left(\left|\varepsilon_{t}\right|\right) \text { if } \varepsilon_{t} \geq 0 \\
(\theta-\gamma) \varepsilon_{t}-\gamma E\left(\left|\varepsilon_{t}\right|\right) \text { if } \varepsilon_{t}<0
\end{array}\right.
$$

$\operatorname{An} \operatorname{EGARCH}(m, s)$ model, according to Tsay (2005), Dhamija and Bhalla (2010), Jiang (2012), Ali (2013) and Grek (2014), can be written as

$$
a_{t}=\sigma_{t} \varepsilon_{t}, \quad \ln \left(\sigma_{t}^{2}\right)=\omega+\sum_{i=1}^{s} \alpha_{i} \frac{\left|a_{t-i}\right|+\theta_{i} a_{t-i}}{\sigma_{t-i}}+\sum_{j=1}^{m} \beta_{j} \ln \left(\sigma_{t-i}^{2}\right),
$$

Which specifically results in EGARCH $(1,1)$ being written as

$$
\begin{gathered}
a_{t}=\sigma_{t} \varepsilon_{t} \\
\ln \left(\sigma_{t}^{2}\right)=\omega+\alpha\left(\left[a_{t-1} \mid-E\left(\left|a_{t-1}\right|\right)\right]\right)+\theta a_{t-1}+\beta \ln \left(\sigma_{t-1}^{2}\right)
\end{gathered}
$$


where $\left|a_{t-1}\right|-E\left(\left|a_{t-1}\right|\right)$ are iid and have mean zero. When the EGARCH model has a Gaussian distribution of error term, then $E\left(\left|\varepsilon_{t}\right|\right)=\sqrt{2 / \pi}$, which gives:

$$
\ln \left(\sigma_{t}^{2}\right)=\omega+\alpha\left(|| a_{t-1} \mid-\sqrt{2 / \pi}\right)+\theta a_{t-1}+\beta \ln \left(\sigma_{t-1}^{2}\right)
$$

\subsection{The Absolute Value GARCH (AVGARCH):}

An asymmetric GARCH (AGARCH), according to Ali (2013) is simply

$$
a_{t}=\sigma_{t} \varepsilon_{t} ; \sigma^{2}=\omega+\sum_{i=1}^{p} \alpha_{i}\left|\varepsilon_{t-i}-b\right|^{2}+\sum_{j=1}^{q} \beta_{j} \sigma_{t-j}^{2},
$$

While the absolute value generalized autoregressive conditional heteroskedasticity (AVGARCH) model is specified as:

$$
a_{t}=\sigma_{t} \varepsilon_{t} ; \quad \sigma^{2}=\omega+\sum_{i=1}^{p} \alpha_{i}\left(\left|\varepsilon_{t-i}+b\right|-c\left(\varepsilon_{t-i}+b\right)\right)^{2}+\sum_{j=1}^{q} \beta_{j} \sigma_{t-j}^{2}
$$

\subsection{Nonlinear (Asymmetric) GARCH, or N(A)GARCH or NAGARCH}

NAGARCH plays key role in option pricing with stochastic volatility because, as we shall see later on, NAGARCH allows you to derive closed-form expressions for European option prices in spite of the rich volatility dynamics. Because a NAGARCH may be written as

$$
\sigma_{t+1}^{2}=\omega+\alpha \sigma_{t}^{2}\left(z_{t}-\delta\right)^{2}+\beta \sigma_{t}^{2}
$$

And if $z_{t} \sim \operatorname{IIDN}(0,1), z_{t}$ is independent of $\sigma_{t}^{2}$ as $\sigma_{t}^{2}$ is only a function of an infinite number of past squared returns, it is possible to easily derive the long run, unconditional variance under NGARCH and the assumption of stationarity:

$$
\begin{aligned}
& E\left[\sigma_{t+1}^{2}\right]=\bar{\sigma}^{2}=\omega+\alpha E\left[\sigma_{t}^{2}\left(z_{t}-\delta\right)^{2}\right]+\beta E\left[\sigma_{t}^{2}\right] \\
& =\omega+\alpha E\left[\sigma_{t}^{2}\right] E\left(z_{t}^{2}+\delta^{2}-2 \delta z_{t}\right]+\beta E\left[\sigma_{t}^{2}\right] \\
& =\omega+\alpha \bar{\sigma}^{2}\left(1+\delta^{2}\right)+\beta \bar{\sigma}^{2}
\end{aligned}
$$

Where $\bar{\sigma}^{2}=E\left[\sigma_{t}^{2}\right]$ and $E\left[\sigma_{t}^{2}\right]=E\left[\sigma_{t+1}^{2}\right]$ because of stationary. Therefore

$$
\bar{\sigma}^{2}\left[1-\alpha\left(1+\delta^{2}\right)+\beta\right]=\omega \Rightarrow \bar{\sigma}^{2}=\frac{\omega}{1-\alpha\left(1+\delta^{2}\right)+\beta}
$$


Which exists and positive if and only if $\alpha\left(1+\delta^{2}\right)+\beta<1$. This has two implications:

(i) The persistence index of a NAGARCH$(1,1)$ is $\alpha\left(1+\delta^{2}\right)+\beta$ and not simply $\alpha+\beta$;

(ii) a NAGARCH $(1,1)$ model is stationary if and only if $\alpha\left(1+\delta^{2}\right)+\beta<1$.

See details in Nelson (1991); Hall \& Yao (2003); Enders (2004); Christoffersen, et al. (2008) and Engle \& Rangel (2008).

\subsection{Materials and Methods}

The data used in this study was collected from www.cashcraft.com under stock trend and analysis. Daily stock price for Total Petroleum Nigeria plc from January $2^{\text {nd }} 2001$ to May $8^{\text {th }}$ 2017 (a total of 4016 observations) was collected from the website. The returns was calculated using the formula below

$$
R_{t}=\ln P_{t-1}-\ln P_{t-1} .
$$

Then a total observation becomes 4015 .

\subsection{Results and Discussions}

The analyses of this study was carried in $\mathrm{R}$ environment using rugarch package by Ghalanos (2018) and PerformanceAnalytics package by Peterson et al.(2018). The section begins with the descriptive statistics of the daily stock price of Total Nigeria, plc. Figures 1, 2 and 3 presents the daily stock price of Total, its log transform and log returns of Total Nigeria Plc. The fig 3 shows some level of stability except in few cases. Table 1 shows the descriptive statistics of the Daily stock price of total, its log transform and log returns of total Nigeria plc and they all exhibited the characteristics of financial time series and the variables were not normally distributed at 5\% level of significance (i.e evidence of volatility) ( Abdulkareem \& Abdulkareem, 2016). 


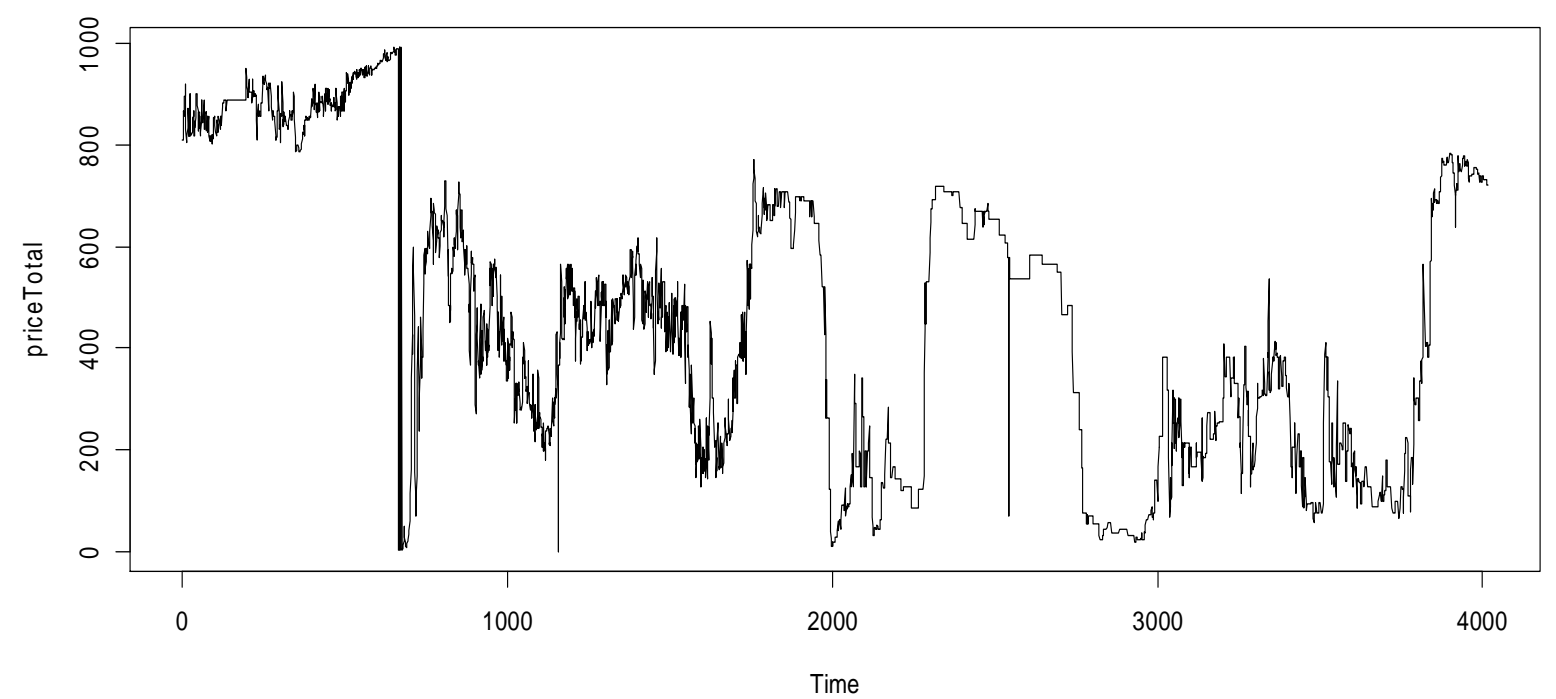

Fig 1: Plot of Total Stock price

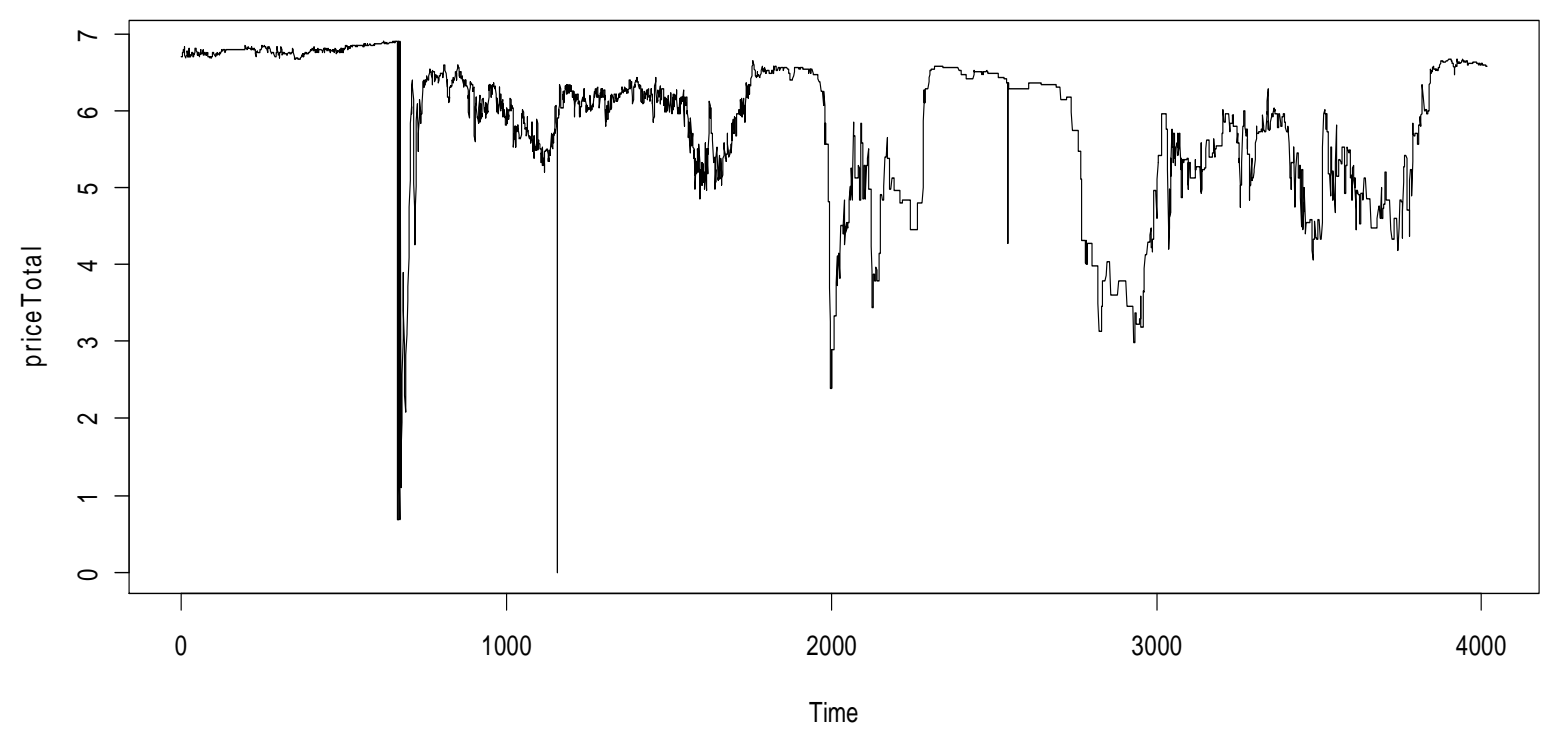

Fig 2: Plot of log transform of Total stock price and log returns of Total respectively. 


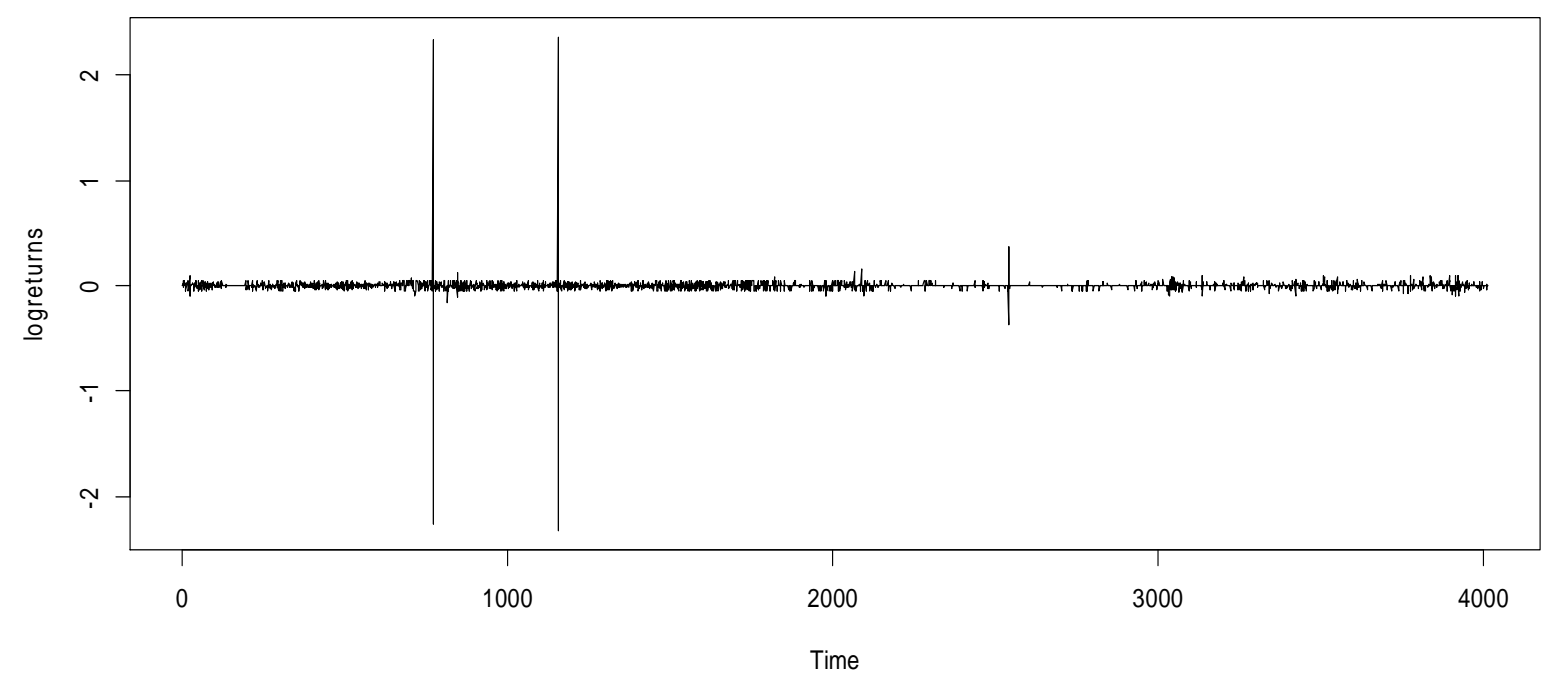

Fig 3: Plot of log returns of Total stock price 
Table 1: Summary Statistics Daily stock Price and Returns of Total Nigeria Plc

\begin{tabular}{|c|c|c|c|}
\hline Statistics & Actual Daily Stock Price & Log of Daily Stock Price & Log of returns of Daily Stock price \\
\hline Min & 1 & 0 & -2.31941 \\
\hline $\operatorname{Max}$ & 991 & 6.898715 & 2.35569 \\
\hline Median & 456.5 & 6.123588 & 0 \\
\hline Mean & 460.261 & 5.825807 & 0.0003562615 \\
\hline Estimated sd & 280.7877 & 0.9404331 & 0.07709386 \\
\hline Estimated skewness & 0.1352331 & -1.374364 & 0.8949538 \\
\hline Estimated kurtosis & 1.81057 & 5.314982 & 814.9014 \\
\hline $\begin{array}{l}\text { Jarque-Bera Normality } \\
\text { Test }\end{array}$ & $\begin{array}{l}\mathrm{X} \text {-squared: } 248.9706 \\
\mathrm{p} \text { Value }:<2.2 \mathrm{e}-16\end{array}$ & $\begin{array}{l}\mathrm{X} \text {-squared: } 2156.7212 \\
\mathrm{p} \text { Value: }<2.2 e-16\end{array}$ & $\begin{array}{l}\mathrm{X} \text {-squared: } 110001718.9071 \\
\mathrm{p} \text { Value: }<2.2 \mathrm{e}-16\end{array}$ \\
\hline Number of Observations & 4016 & 4016 & 4015 \\
\hline
\end{tabular}

Table 2: GARCH Models and Their Performance on the Log Returns of Daily Stock price of Total Nigeria Plc

\begin{tabular}{|c|c|c|c|}
\hline Model & Information criteria & Normal innovation & Student $\mathrm{t}$ innovation \\
\hline sGARCH $(1,1)$ & $\begin{array}{l}\text { Akaike } \\
\text { Bayes } \\
\text { Shibata } \\
\text { Hannan-Quinn }\end{array}$ & $\begin{array}{l}-4.7049 \\
-4.7002 \\
-4.7049 \\
-4.7032\end{array}$ & N.A \\
\hline gjrGARCH $(1,1)$ & $\begin{array}{l}\text { Akaike } \\
\text { Bayes } \\
\text { Shibata } \\
\text { Hannan-Quinn }\end{array}$ & $\begin{array}{l}-4.7103 \\
-4.7040 \\
-4.7103 \\
-4.7081\end{array}$ & N.A \\
\hline eGARCH $(1,1)$ & $\begin{array}{l}\text { Akaike } \\
\text { Bayes } \\
\text { Shibata } \\
\text { Hannan-Quinn }\end{array}$ & $\begin{array}{l}-4.7221 \\
-4.7158 \\
-4.7221 \\
-4.7199\end{array}$ & $\begin{array}{l}-5.6080 \\
-5.6002 \\
-5.6080 \\
-5.6052\end{array}$ \\
\hline
\end{tabular}




\begin{tabular}{|l|l|l|l|}
\hline iGARCH $(1,1)$ & Akaike & -4.6949 & -6.1100 \\
& Bayes & -4.6918 & -6.1053 \\
& Shibata & -4.6949 & -6.1100 \\
& Hannan-Quinn & -4.6938 & -6.1084 \\
\hline apARCH $(1,1)$ & Akaike & -4.7111 & -9.3760 \\
& Bayes & -4.7033 & -9.3666 \\
& Shibata & -4.7111 & -9.3760 \\
& Hannan-Quinn & -4.7083 & -9.3727 \\
\hline TGARCH $(1,1)$ & Akaike & -2.0986 & -7.6480 \\
& Bayes & -2.0923 & -7.6402 \\
& Shibata & -2.0986 & -7.6480 \\
& Hannan-Quinn & -2.0964 & -7.6452 \\
\hline NGARCH (1,1) & Akaike & -4.7057 & $\mathbf{- 2 2 . 0 5 7}$ \\
& Bayes & -4.6994 & $\mathbf{- 2 2 . 0 4 9}$ \\
& Shibata & -4.7057 & $\mathbf{- 2 2 . 0 5 7}$ \\
& Hannan-Quinn & -4.7034 & $\mathbf{- 2 2 . 0 5 4}$ \\
\hline NAGARCH (1,1) & Akaike & -4.7068 & -6.0847 \\
& Bayes & -4.7006 & -6.0768 \\
& Shibata & -4.7068 & -6.0847 \\
& Hannan-Quinn & -4.7046 & $\mathbf{- 6 . 0 8 1 9}$ \\
\hline & Akaike & -4.7068 & -7.3255 \\
& Bayes & -4.6990 & -7.3160 \\
& Shibata & -4.7068 & -7.3255 \\
& Hannan-Quinn & -4.7040 & $\mathbf{- 7 . 3 2 2 1}$ \\
\hline
\end{tabular}


The log returns of the daily stock price of total Nigeria Plc was modeled with 9 (Nine) different GARCH models (sGARCH, gjrGARCH, eGARCH, iGARCH, aPARCH, TGARCH, NGARCH, NAGARCH and AVGARCH) in Table 2 above. We used GARCH(1,1) because many study have found its usefulness and performance (Bollerslev, (1986); Gonzalez-Rivera, et al.(2004); Panait \& Slavescu, (2012)). Using Akaike Information Criterion (AIC) the eGARCH outperformed other models for normal innovation while for student $\mathrm{t}$ innovation; the NGARCH model outperformed other models. The performance of NGARCH is in line with the work of Emenogu and Adenomon (2018). Table 3 below shows the persistence and half-life volatility of the models. The persistence values of the models revealed the stability of the model except for iGARCH that has its value as 1 (one). This means that the volatility of the Total Nigeria Plc daily stock price and returns can be modeled and can be forecasted. For normal innovation, The half life of the models sGARCH, gjrGARCH, eGARCH, aPARCH, TGARCH, NGARCH, NAGARCH and AVGARCH for mean reverting takes about 7 days, 8 days, 4 days, 7 days, 90 days, 6 days, 7 days and 5 days respectively. This should boost the confidence of the stock holders of Total Nigeria plc that any seemingly falls in the price of the stock can be regained in the future. For student t innovation, sGARCH and gjrGARCH values for persistence and half-life volatility are not available while iGARCH persistence value is equal to $1(\mathrm{one})$. While eGARCH, aPARCH, TGARCH, NGARCH, NAGARCH and AVGARCH models are stable with half- life of about 1031 days, 19 days, 2 days, 38 days, 11 days and 3 days respectively.

Table 3: persistence and half-life volatility of log Returns of Daily Stock Price of Total Nigeria, Plc.

\begin{tabular}{|c|c|c|c|c|}
\hline & \multicolumn{2}{|c|}{ Normal innovation } & \multicolumn{2}{c|}{ Student t innovation } \\
\hline & Persistence & Half-life volatility & Persistence & Half-life volatility \\
\hline sGARCH $(1,1)$ & 0.8985037 & 6.47653 & NA & NA \\
\hline gjrGARCH $(1,1)$ & 0.906777 & 7.083141 & NA & NA \\
\hline eGARCH $(1,1)$ & 0.8242379 & 3.585935 & 0.9993276 & 1030.535 \\
\hline iGARCH $(1,1)$ & 1 & Infinity & 1 & Infinity \\
\hline apARCH $(1,1)$ & 0.8959709 & 6.310093 & 0.9637551 & 18.77531 \\
\hline TGARCH $(1,1)$ & 0.9922771 & 89.40491 & 0.62996 & 1.499997 \\
\hline NGARCH $(1,1)$ & 0.885314 & 5.690259 & 0.981578 & 37.27836 \\
\hline
\end{tabular}




\begin{tabular}{|l|l|l|l|l|}
\hline NAGARCH $(1,1)$ & 0.9008652 & 6.639366 & 0.9364346 & 10.5541 \\
\hline AVGARCH $(1,1)$ & 0.854636 & 4.412711 & 0.7293367 & 2.196146 \\
\hline
\end{tabular}

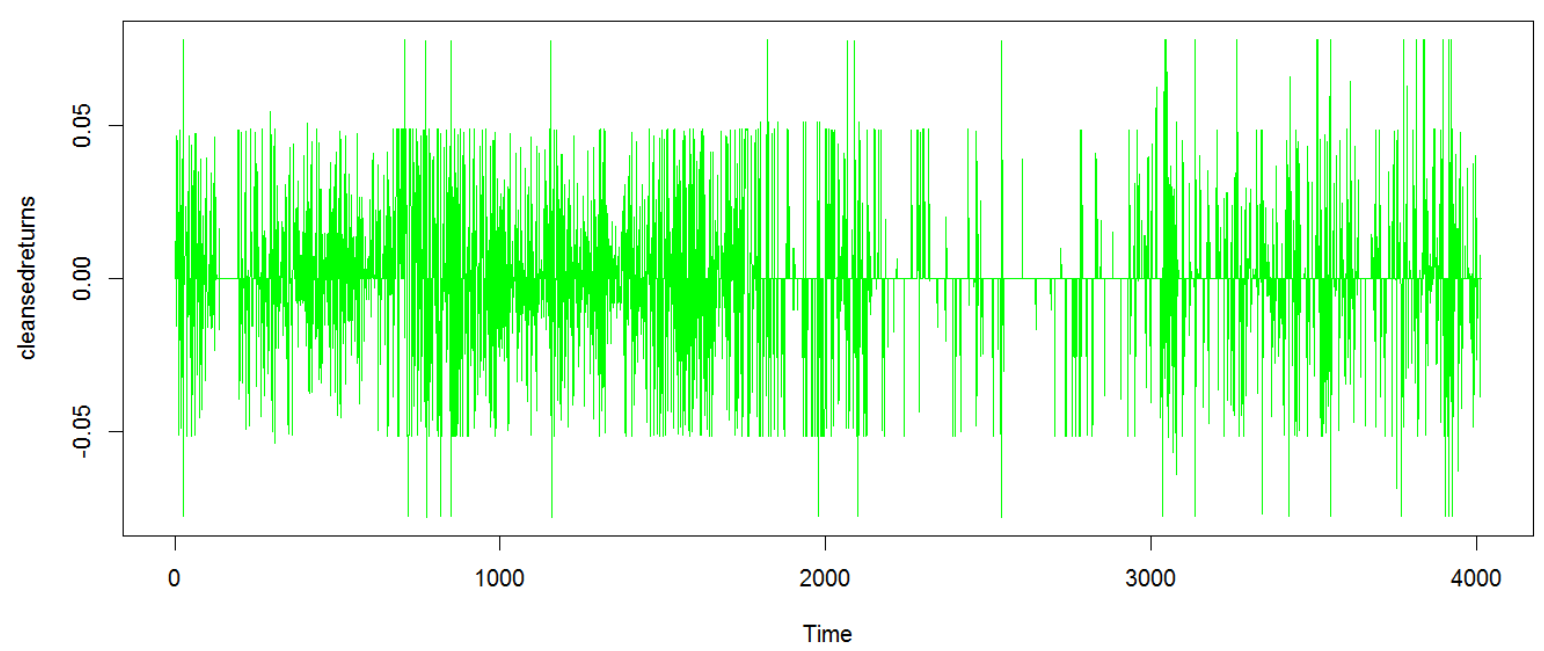

Fig 4: Plot Cleansed log Returns of Total Stock

Figure 4 above presents the Cleansed log Returns of Total Stock price, this is done to reduce the effects of outliers (Peterson et al., 2018).

Table 4: Descriptive Statistics of the Cleansed Returns of Daily Stock Price of Total Nigeria, Plc

\begin{tabular}{|l|l|}
\hline Statistics & Cleansed Returns of Total Plc \\
\hline Min & -0.07782726 \\
Max & 0.07800604 \\
Median & 0 \\
Eean & 0.0003082449 \\
Estimated sd & 0.02235972 \\
Estimated kurtosis & -0.002263221 \\
Jarque-Bera Normality Test & X-squared: 632.2164 Asymptotic \\
& p Value: $<2.2 e-16$ \\
Number of Observations & 4015 \\
\hline
\end{tabular}


The the descriptive statistics of the cleansed retuns of total Nigeria, Plc in table 4 table above also exhibits the characteristics of financial time series.

Table 5: GARCH Models and Their Performance on the Cleansed Log Returns of Daily Stock price of Total Nigeria Plc

\begin{tabular}{|c|c|c|c|}
\hline Model & Information criteria & Normal innovation & Student $\mathrm{t}$ innovation \\
\hline sGARCH $(1,1)$ & $\begin{array}{l}\text { Akaike } \\
\text { Bayes } \\
\text { Shibata } \\
\text { Hannan-Quinn }\end{array}$ & $\begin{array}{l}-4.9438 \\
-4.9391 \\
-4.9438 \\
-4.9421\end{array}$ & NA \\
\hline g jrGARCH $(1,1)$ & $\begin{array}{l}\text { Akaike } \\
\text { Bayes } \\
\text { Shibata } \\
\text { Hannan-Quinn }\end{array}$ & $\begin{array}{l}-4.9434 \\
-4.9371 \\
-4.9434 \\
-4.9411\end{array}$ & $\mathrm{NA}$ \\
\hline eGARCH $(1,1)$ & $\begin{array}{l}\text { Akaike } \\
\text { Bayes } \\
\text { Shibata } \\
\text { Hannan-Quinn }\end{array}$ & $\begin{array}{l}-4.9401 \\
-4.9338 \\
-4.9401 \\
-4.9379\end{array}$ & $\begin{array}{l}-5.8066 \\
-5.7988 \\
-5.8066 \\
-5.8039\end{array}$ \\
\hline$i \operatorname{GARCH}(1,1)$ & $\begin{array}{l}\text { Akaike } \\
\text { Bayes } \\
\text { Shibata } \\
\text { Hannan-Quinn }\end{array}$ & $\begin{array}{l}-4.9363 \\
-4.9331 \\
-4.9363 \\
-4.9352\end{array}$ & $\begin{array}{l}-6.3708 \\
-6.3661 \\
-6.3708 \\
-6.3691\end{array}$ \\
\hline $\operatorname{apARCH}(1,1)$ & $\begin{array}{l}\text { Akaike } \\
\text { Bayes } \\
\text { Shibata } \\
\text { Hannan-Quinn }\end{array}$ & $\begin{array}{l}-4.9429 \\
-4.9350 \\
-4.9429 \\
-4.9401\end{array}$ & $\begin{array}{l}-12.693 \\
-12.684 \\
-12.693 \\
-12.690\end{array}$ \\
\hline $\operatorname{TGARCH}(1,1)$ & $\begin{array}{l}\text { Akaike } \\
\text { Bayes } \\
\text { Shibata } \\
\text { Hannan-Quinn }\end{array}$ & $\begin{array}{l}-2.8546 \\
-2.8483 \\
-2.8546 \\
-2.8523\end{array}$ & $\begin{array}{l}-7.5955 \\
-7.5876 \\
-7.5955 \\
-7.5927\end{array}$ \\
\hline NGARCH $(1,1)$ & $\begin{array}{l}\text { Akaike } \\
\text { Bayes } \\
\text { Shibata } \\
\text { Hannan-Quinn }\end{array}$ & $\begin{array}{l}-4.9433 \\
-4.9370 \\
-4.9433 \\
-4.9411\end{array}$ & $\begin{array}{l}-21.080 \\
-21.072 \\
-21.080 \\
-21.077\end{array}$ \\
\hline NAGARCH $(1,1)$ & $\begin{array}{l}\text { Akaike } \\
\text { Bayes } \\
\text { Shibata } \\
\text { Hannan-Quinn }\end{array}$ & $\begin{array}{l}-4.9433 \\
-4.9371 \\
-4.9433 \\
-4.9411\end{array}$ & $\begin{array}{l}-6.3209 \\
-6.3131 \\
-6.3209 \\
-6.3181\end{array}$ \\
\hline $\operatorname{AVGARCH}(1,1)$ & $\begin{array}{l}\text { Akaike } \\
\text { Bayes } \\
\text { Shibata } \\
\text { Hannan-Quinn }\end{array}$ & $\begin{array}{l}-4.9363 \\
-4.9284 \\
-4.9363 \\
-4.9335\end{array}$ & $\begin{array}{l}-8.0452 \\
-8.0358 \\
-8.0452 \\
-8.0419\end{array}$ \\
\hline
\end{tabular}


The cleansed log returns of the daily stock price of total Nigeria Plc was modeled with 9 (Nine) different GARCH models (sGARCH, gjrGARCH, eGARCH, iGARCH, aPARCH, TGARCH, NGARCH, NAGARCH and AVGARCH) in Table 5 above. We used GARCH $(1,1)$ because many study have found its usefulness and performance (Bollerslev, (1986); GonzalezRivera, et al.(2004); Panait \& Slavescu, (2012)). Using Akaike Information Criterion (AIC) the sGARCH outperformed other models for normal innovation while for student $t$ innovation; the NGARCH model outperformed other models. The performance of NGARCH is in line with the work of Emenogu and Adenomon (2018). Table 6 below shows the persistence and half-life volatility of the models. The persistence values of the models revealed the stability of the model except for iGARCH that has its value as 1 (one). This means that the volatility of the cleansed Total Nigeria Plc daily stock price can be modeled and can be forecasted. For normal innovation, the half -life of the models sGARCH, gjrGARCH, eGARCH, aPARCH, TGARCH, NGARCH, NAGARCH and AVGARCH for mean reverting takes about 33 days, 33 days, 9 days, 33 days, 172 days, 33 days, 33 days and 18 days respectively. This should boost the confidence of the stock holders of Total Nigeria plc that any seemingly falls in the price of the stock can be regained in the future. For student $t$ innovation, sGARCH and gjrGARCH values for persistence and half-life volatility are not available while eGARCH and iGARCH persistence values are equal to 1(one). While aPARCH, TGARCH, NGARCH, NAGARCH and AVGARCH models are stable with half- life of about 21 days, 2 days, 47 days, 7 days, and 2 days respectively. The performance of NGARCH model for student $t$ innovation for cleansed daily stock returns is similar to that of log returns of Total Nigeria, plc.

Table 6: persistence and half-life volatility of the cleansed log Returns of Daily Stock Price of Total Nigeria, Plc.

\begin{tabular}{|l|l|l|l|l|}
\hline & \multicolumn{2}{|l|}{ Normal innovation } & Student t innovation \\
\hline & Persistence & Half-life volatility & Persistence & Half-life volatility \\
\hline sGARCH $(1,1)$ & 0.9791448 & 32.88842 & NA & NA \\
\hline gjrGARCH $(1,1)$ & 0.9790591 & 32.7524 & NA & NA \\
\hline eGARCH $(1,1)$ & 0.918747 & 8.17926 & 1 & Infinity \\
\hline iGARCH $(1,1)$ & 1 & Infinity & 1 & Infinity \\
\hline apARCH $(1,1)$ & 0.9790893 & 32.80017 & 0.9667162 & 20.47685 \\
\hline
\end{tabular}




\begin{tabular}{|l|l|l|l|l|}
\hline TGARCH $(1,1)$ & 0.9959671 & 171.5258 & 0.6386781 & 1.545979 \\
\hline NGARCH $(1,1)$ & 0.9791485 & 32.89425 & 0.9850743 & 46.09227 \\
\hline NAGARCH $(1,1)$ & 0.9790062 & 32.66894 & 0.8924189 & 6.089872 \\
\hline AVGARCH $(1,1)$ & 0.9611715 & 17.50263 & 0.5455017 & 1.143714 \\
\hline
\end{tabular}

\subsection{Value-at Risk (VaR) Analysis of Total daily Stock Returns}

$\mathrm{VaR}$ analysis is important for two reasons: first it provides a common consistent measure of risk for stock returns and second, it takes into account the correlation between risk factors (Nieppola, 2009). In this study, the in-sample VaR was calculated using normal distribution. The choice of in-sample is for the purpose of large data set while for out-of-sample VaR calculation will be done in the next 2 to 3 years to be able to obtain a data set of about 1000 time series length.

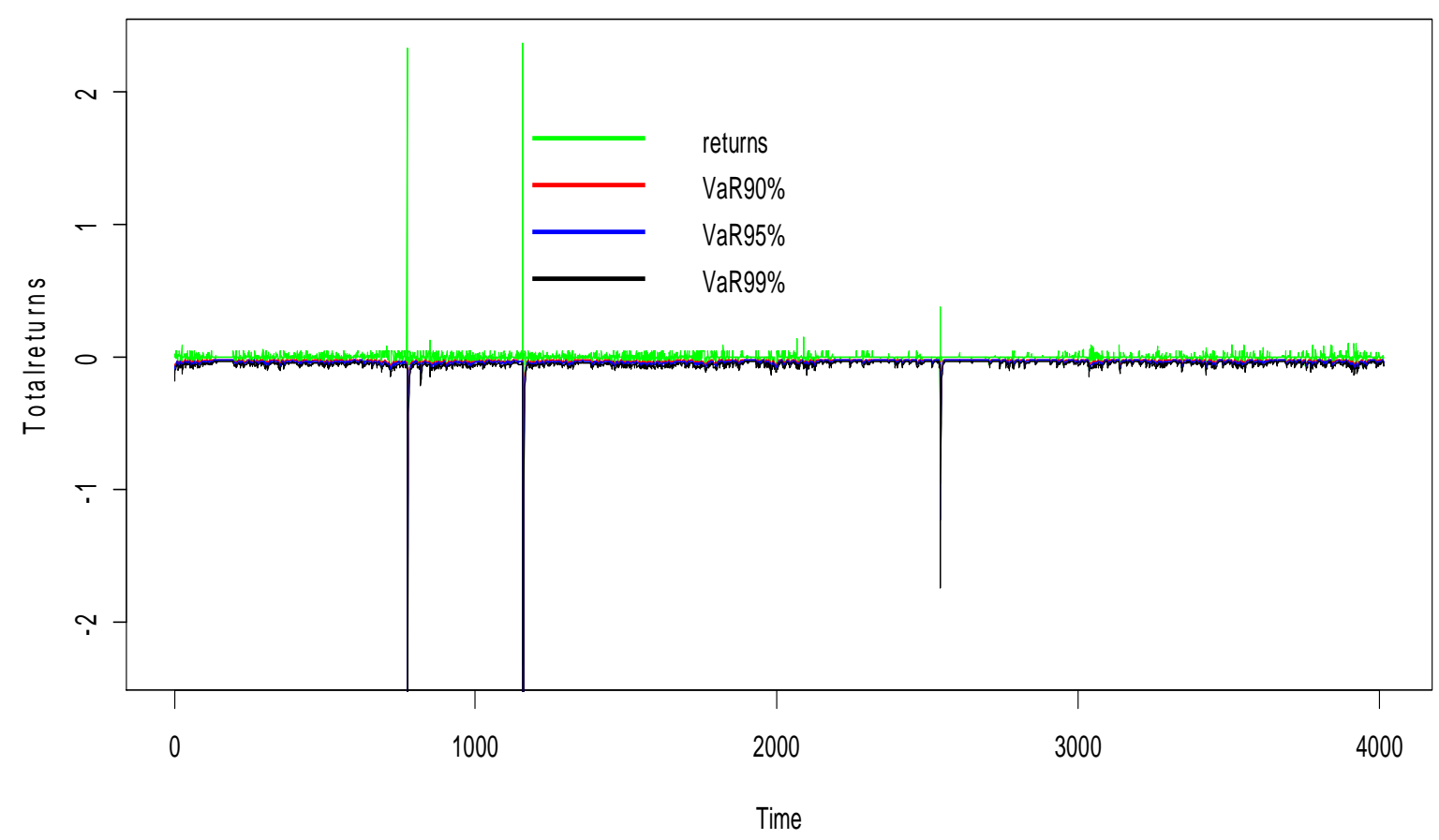

Fig 5: eGARCH( $(1,1)$ with normal innovation

In figure 5 above, the VaR values are less than the returns for eGARCH model. In addition, the percentage of $\mathrm{VaR}$ violation (see Table 7 below) at $1 \%$ is $2.1 \%$ making the model to be rejected, 
while at $5 \%$ the model is slightly rejected but at $10 \%$ the model is accepted having VaR violation of $8.5 \%$.

Table 7: VaR Violation of the Actual Total Returns

\begin{tabular}{|l|l|l|l|l|}
\hline Model & VaR alpha & No. of Violation & Ratio & Percentage \\
\hline eGARCH(1,1) & $1 \%$ & 86 & $86 / 4015$ & $2.1 \%$ \\
with normal & $5 \%$ & 216 & $216 / 4015$ & $5.4 \%$ \\
& $10 \%$ & 340 & $340 / 4015$ & $8.5 \%$ \\
\hline NGARCH(1,1) & $1 \%$ & 85 & $85 / 4015$ & $2.1 \%$ \\
With std & $5 \%$ & 206 & $206 / 4015$ & $5.1 \%$ \\
& $10 \%$ & 320 & $320 / 4015$ & $8.0 \%$ \\
\hline
\end{tabular}

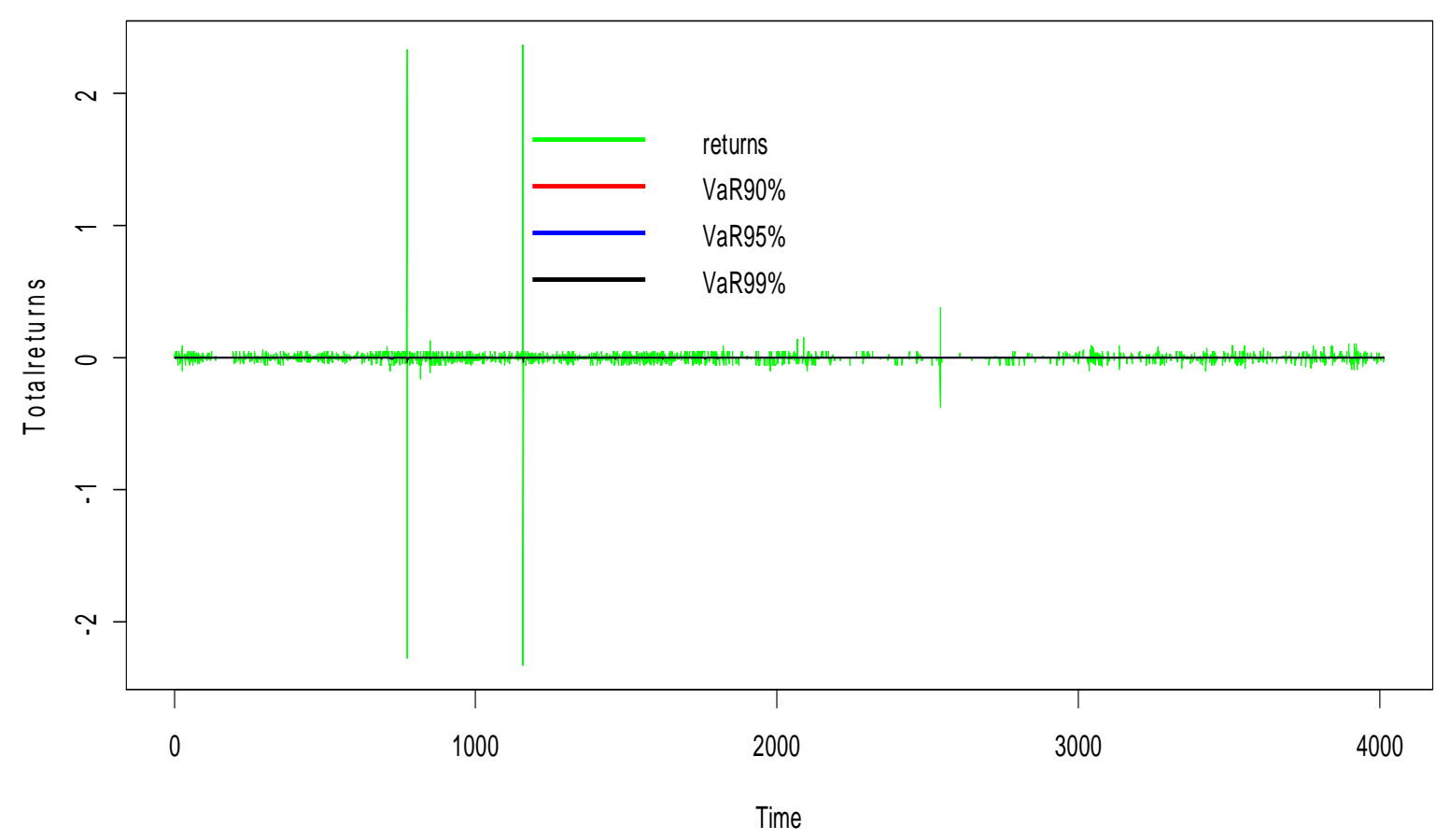

Fig 6: NGARCH $(1,1)$ with student $t$ distribution

In figure 6 above, the VaR values are less than the returns for NGARCH model. In addition, the percentage of $\mathrm{VaR}$ violation (see Table 7 above) at $1 \%$ is $2.1 \%$ making the model to be rejected, 
while at $5 \%$ the model is slightly rejected but at $10 \%$ the model is accepted having VaR violation of $8.0 \%$.

The above results from VaR analysis for the log Retuns of Total means that VaR calculation for eGARCH model with normal innovation and NGARCH model with student $\mathrm{t}$ innovation are rejected with $99 \%$ confidence level and slighly rejected with $95 \%$ confidence level and accepted with $90 \%$ confidence level. Meaning the risk is high at $1 \%$ level of significance.

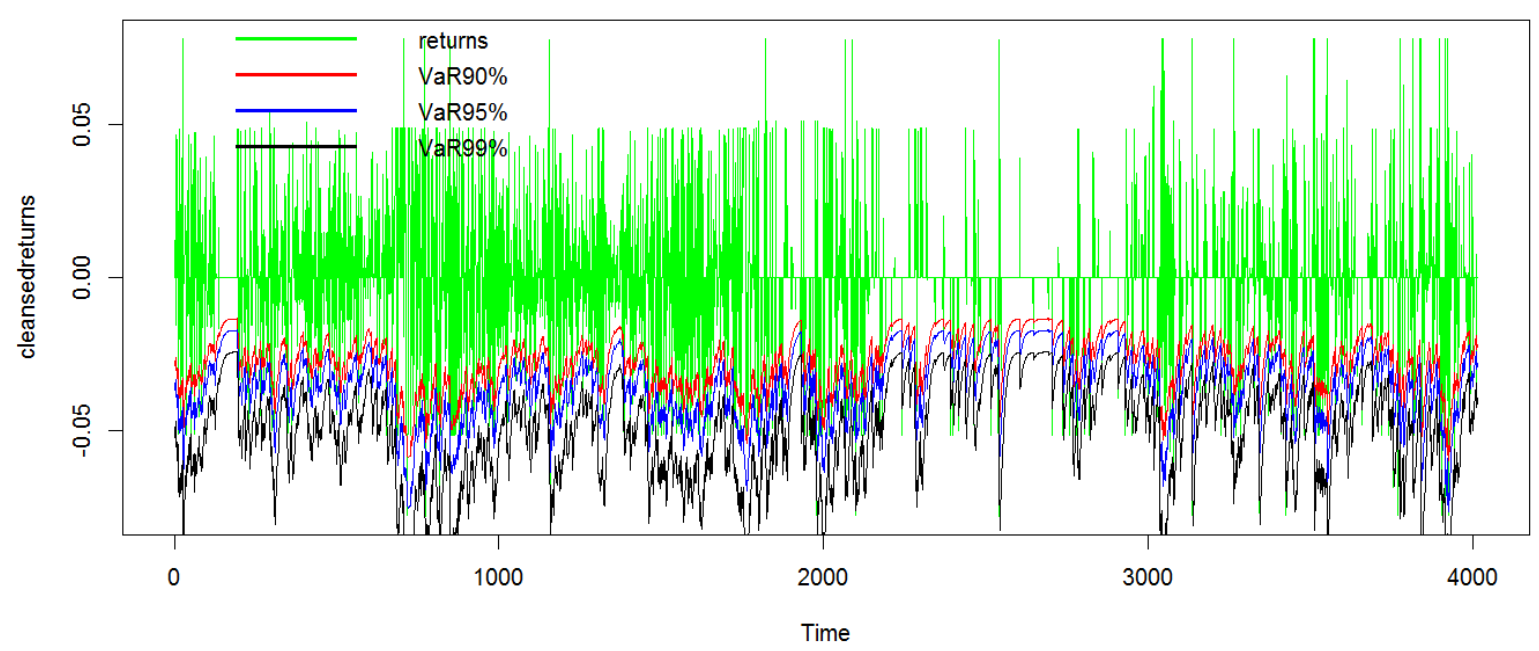

Fig 7: Plot of Cleansed stocks returns and VaR calculation from $\operatorname{sGARCH}(1,1)$ with normal innovation

In figure 7 above, the VaR values are less than the returns for sGARCH model. In addition, the percentage of $\mathrm{VaR}$ violation (see Table 8 below) at $1 \%$ is $2.2 \%$ making the model to be rejected, while at $5 \%$ the model is slightly rejected but at $10 \%$ the model is accepted having VaR violation of $7.9 \%$.

Table 8: VaR Violation of Cleansed Total Returns

\begin{tabular}{|l|l|l|l|l|}
\hline Model & VaR alpha & No. of Violation & Ratio & Percentage \\
\hline sGARCH(1,1) & $1 \%$ & 88 & $88 / 4015$ & $2.2 \%$ \\
with normal & $5 \%$ & 203 & $203 / 4015$ & $5.1 \%$ \\
& $10 \%$ & 319 & $319 / 4015$ & $7.9 \%$ \\
\hline
\end{tabular}




\begin{tabular}{|l|l|l|l|l|}
\hline NGARCH(1,1) & $1 \%$ & 960 & $960 / 4015$ & $23.9 \%$ \\
With std & $5 \%$ & 971 & $971 / 4015$ & $24.2 \%$ \\
& $10 \%$ & 974 & $974 / 4015$ & $24.3 \%$ \\
\hline
\end{tabular}

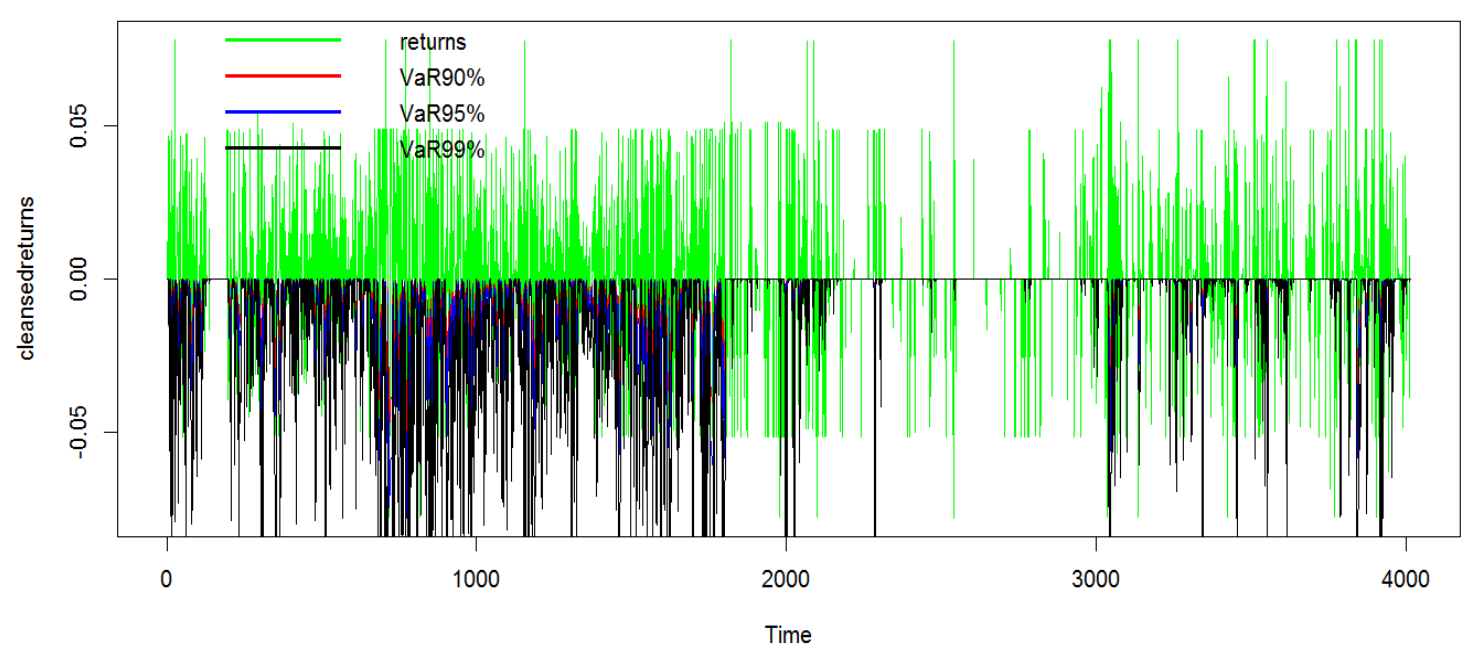

Fig 8: Plot of Cleansed stocks returns and VaR calculation from $\operatorname{NGARCH}(1,1)$ with Student $t$ innovation

In figure 8 above, the $\mathrm{VaR}$ values are less than the returns for $\mathrm{NGARCH}$ model. In addition, the percentage of $\mathrm{VaR}$ violation (see Table 8 above) revealed strange results as the model is rejected at all confidence levels and the perecentages of violation are very high.

\subsection{Backtesting Value-at-Risk (VaR) Model}

Financial risk model evaluation or backtesting is an important part of the internal model's approach to market risk management as put out by Basle Committee on Banking Supervision (Christoffersen \& Pelletier, 2004). Backtesting is a statistical procedure where actual profits and losses are systematically compared to corresponding VaR estimates (Nieppola, 2009). This study adopted Backstesting techniques of Christoffersen \& Pelletier, (2004); The VARTest in rugarch package in $\mathrm{R}$ that implements both the unconditional (Kupiec) and conditional (Christoffersen) coverage tests for the correct number of exceedances (see details in Christoffersen(1998) and Christoffersen et al. (2001)). 
First, we conducted Duration-Based Tests of independence. Under the null hypothesis that the risk model is correctly specified, the no-hit duration should have no memory of $1 / \mathrm{p}$ days. This test is suitable for a series with a length of at least 1000 .

Table 9: Implements the VaR Duration Test of Christoffersen and Pelletier on Total Returns

$\mathrm{H}_{0}$ : "Duration Between Exceedances have no memory (Weibull $\mathrm{b}=1=$ Exponential)"

\begin{tabular}{|l|l|l|l|l|l|l|}
\hline Model & VaR alpha & $\mathrm{b}$ & $\mathrm{uLL}$ & $\mathrm{rLL}$ & LRp & Decision \\
\hline eGARCH(1,1) & $1 \%$ & 0.9113497 & -411.8762 & -412.687 & 0.2028727 & Accept \\
with normal & $5 \%$ & 1.060426 & -843.6371 & -844.3382 & 0.2363337 & Accept \\
& $10 \%$ & 1.035284 & -1176.545 & -1176.938 & 0.3757885 & Accept \\
\hline NGARCH(1,1) & $1 \%$ & 0.883668 & -407.4371 & -408.826 & 0.09558002 & Accept \\
With std & $5 \%$ & 1.002159 & -814.8295 & -814.8304 & 0.9660097 & Accept \\
& $10 \%$ & 0.9996276 & -1126.9 & -1126.9 & 0.9925736 & Accept \\
\hline
\end{tabular}

Table 10: Implements the VaR Duration Test of Christoffersen and Pelletier on Cleansed Total returns

$\mathrm{H}_{0}$ : "Duration Between Exceedances have no memory (Weibull $\mathrm{b}=1=$ Exponential)"

\begin{tabular}{|l|l|l|l|l|l|l|}
\hline Model & VaR alpha & $\mathrm{b}$ & uLL & rLL & LRp & Decision \\
\hline sGARCH(1,1) & $1 \%$ & 0.9277124 & -419.8567 & -420.374 & 0.3090839 & Accept \\
with normal & $5 \%$ & 1.038666 & -805.6184 & -805.884 & 0.4660591 & Accept \\
& $10 \%$ & 1.006311 & -1124.353 & -1124.366 & 0.8754419 & Accept \\
\hline NGARCH(1,1) & $1 \%$ & 0.9973736 & -2332.186 & -2332.194 & 0.9029743 & Accept \\
With std & $5 \%$ & 0.9940543 & -2347.843 & -2347.882 & 0.7805672 & Accept \\
& $10 \%$ & 0.9935513 & -2352.093 & -2352.139 & 0.7619914 & Accept \\
\hline
\end{tabular}

The Duration-Based Tests of independence conducted (in Tables 9 and 10) revealed that the models are correctly specified since in all cases the null hypotheses were accepted. This means that the probability of an exception on any day did not depends on the outcome of the previous day. This will go a long way to boost the confidence of shareholders of Total stock in Nigeria. A more detail backtesting technique is the conditional and uncondition coverage rate $\begin{array}{llllll}\text { carried out in } & \text { Tables and } 11 \text { below. }\end{array}$ 
Table 11: VaRTest for Total daily stock returns

\begin{tabular}{|l|l|l|l|l|l|l|l|l|l|l|l|l|}
\hline & & & & & & \\
\\
\hline
\end{tabular}

Table 12: VaRTest for cleansed Total stock returns

\begin{tabular}{|l|l|l|l|l|l|l|l|l|l|l|l|l|}
\hline & & & & & \\
\hline \\
\hline
\end{tabular}


The VARTest in rugarch package in $\mathrm{R}$ that implements both the unconditional (Kupiec) and conditional (Christoffersen) coverage tests for the correct number of exceedances for both Total stock returns and cleansed Total returns (results presented in tables 11 and 12). The results rejects the models at $1 \%$ level of significance which is similar to results will obtain in the percentages of violation rates presented in Tables 7 and 8 . This shows that unconditional (Kupiec) and conditional (Christoffersen) coverage tests for the correct number of exceedances are reliable.

\subsection{Conclusion and Recommendations}

This study sets out to investigate the volatility of the stock price of Total Petroleum Nigeria plc using nine (9) GARCH models namely sGARCH, gjrGARCH, eGARCH, iGARCH, aPARCH, TGARCH, NGARCH, NAGARCH and AVGARCH, we also investigated the Valueat-Risk (VaR) and Backtesting of the Models. The aim actually of this study is to boost the confidence of the shareholders and investors of the Total Nigeria plc. To achieve this, daily stock price for Total petroleum Nigeria plc from secondary. The study used both normal and student $t$ innovations, using AIC to select the best model, for normal innovations for log returns and cleansed $\log$ returns of Total plc, the eGARCH and sGARCH models performed best respectively, while NGARCH model performed best for student $t$ innovation for both log returns and cleansed returns of Total plc. the persistence of the models are stable except in few cases where iGARCH, eGARCH where not stable. Also for student $t$ innovation, the sGARCH and gjrGARCH fails to converge. The mean-reverting number of day for the returns of Total Nigeria plc differs from model to model. The performance of NGARCH is in line with the work of Emenogu and Adenomon (2018). Evidence from the VaR Analysis revealed from the selected models revealed that the Risk of VaR losses is high at $99 \%$ confidence level, slightly high at 95\% confidence level and better at 90\% confidence level. Although The Duration-Based Tests of independence conducted revealed that the models are correctly specified since in all cases the null hypotheses were accepted. This means that the probability of an exception on any day did not depends on the outcome of the previous day. Finally, both the unconditional (Kupiec) and conditional (Christoffersen) coverage tests for the correct number of exceedances for both Total stock returns and cleansed Total returns revealed rejection of the models at $1 \%$ level of significance which is similar to results will obtain in the percentages of violation rates. This confirms that unconditional (Kupiec) and conditional (Christoffersen) coverage tests for the 
correct number of exceedances are reliable compared to the Duration-Based Tests of independence (Nieppola, 2009). Therefore we recommend that shareholders and investors in Total Nigeria plc are to remain and continue to investment in Total Nigeria plc because if there is any form of losses, the price of the stock has the potentials to improve in the future. Again, though the risk is high at $99 \%$ confidence level, this in line with the financial theory that states that an asset with high expected risk would pay higher return on the average (Xekalaki and Degiannakis, 2010).

\subsection{Future Study}

We hope to study Total Petroleum Nigeria Plc because of its potential in the Nigeria Stock market. In the future we will examined the stock price with GARCH-Mean Models and More advanced GARCH Models, out-of -sample Value-at-Risk (VaR) and Backtesting.

Also investigate Total Petroleum Nigeria plc stocks in relation to Interest rate, inflation rate, exchange rate and Crude oil price in the global market using Multivariate GARCH (MGARCH) models.

\section{References}

Aas, K. and Dimakos, X. K.(2004): Statistical Modelling of Financial Time Series: An Introduction. NR Note, SAMBA/08/04.

Abdulkareem, A. and Abdulkareem, K. A.(2016): Analyzing Oil Price-Macroeconomic Volatility in Nigeria. CBN Journal of Applied Statistics, 7(1a):1-22.

Adenomon, M. O.(2016): Analysis of Agriculture and Gross Domestic Product of Nigeria using First Difference Regression Model. Journal of Nigerian Statistical Association, 28:42-57.

Ahmadi, M.; Manera, M. and Sadeghzadeh, M. (2018): Investment-Uncertainty Relationship in the Oil and Gas Industry. Fondazione Eni Enrico Mattei (FEEM), 1-14.

Akinlo, O. O. (2014): Oil Price and Stock Market: Empirical Evidence from Nigeria. European Journal of Sustainable Development, 3(2):33-40.

Akinlo, T. and Apanisile, O. T.(2015): The Impact of Volatility of Oil price on the Economic Growth in Sub-Saharan Africa. British Journal of Economics, Management and Trade, 5(3):338-349. 
Ali, G. (2013) "EGARCH, GJR-GARCH, TGARCH, AVGARCH, NGARCH, IGARCH, and APARCH Models for Pathogens at Marine Recreational Sites". Journal of Statistical and Econometric Methods, 2 (3): 57-73.

Alley, I; Asekomeh, A.; Mobolayi, H. \& Adeniran, Y. A.(2014): Oil Price Stocks and Economic Growth. European Scientific Journal, 10(19):375-391.

Asaola, T. O. and Ilo, B. M.(2012): The Nigerian Stock market and oil Price: A Cointegration Analysis. Kuwait Chapter of Arabian Journal of Business and Management Review, 1(5):39-54.

Atoi, N. V. (2014) "Testing volatility in Nigeria stock market using GARCH models". CBN Journal of Applied Statistics, 5: 65-93.

Bali, T. G. and Cakici, N.(2004): Value at Risk and Expected Stock Returns. Financial Analysts Journal, 60(2):57-73.

Best, P.(1998): Implementing Value at Risk. New York: John Wiley \& Sons.

Bollerslev, T. (1986) "Generalized Autoregressive Conditional Heteroskedasticity".Journal of Econometrics. 31: 307-327

Christoffersen, P. (1998), Evaluating Interval Forecasts, International Economic Review, 39, $841-862$.

Christoffersen, P., Hahn,J. and Inoue, A. (2001), Testing and Comparing Value-at-Risk Measures, Journal of Empirical Finance, 8, 325-342.

Christoffersen, P., Jacobs, K., Ornthanalai, C., Wang, Y., (2008). Option valuation with long- run and short-run volatility components. Journal of Financial Economics 90, 272-297.

Christoffersen, P. and Pelletier, D. (2004): Backtesting value-at-risk: A duration-based approach, Journal of Financial Econometrics, 2(1), 84-108.

Corkalo, S.(2011): Comparison of Value at Risk Approaches on a stock Portfolio. Croation Operational Research Review (CRORR), 2:81-90.

Dhamija and Bhalla (2010) "Financial time series forecasting: comparison of neural networks and ARCH models", International Research Journal of Finance and Management, 49 (1), 159-172

Ding, Z, Granger, C. W. J. \& Engle, R. F. (1993) “A long memory property of stock market returns and a new model”, Journal of Empirical Finance, 1, 83-106. 
Emenogu, G. N. and Adenomon, M. O(2018); The Effect of High Positive Autocorrelation on the Performance of GARCH Family Models. Preprints. doi:10.20944/preprints201811.0381.v1

Enders, W., (2004). Applied Econometric Time Series. John Wiley, New York.

Engle, R. F.; Lilien, D. M. and Robins, R. P.(1987): Estimating Time Varying Risk Premia in Term Structure: The ARCH-M Model. Econometrica, 55:391-407.

Engle, R., and Rangel, J., (2008). The spline-GARCH model for low-frequency volatility and its global macroeconomic causes. Review of Financial Studies 21, 1187-1222.

Enocksson, D. and Skoog, J. (2012) Evaluating VaR (Value-at-Risk): with the ARCH/GARCH class models via, European Union: Lambert Academic Publishing (LAP).

Ghalanos, A.(2018): Package 'rugarch'. R Team Cooperation.

Gonzalez-Rivera, G., Lee, T. H., and Mishra, S. 2004, Forecasting volatility: A reality check based on option pricing, utility function, value-at-risk, and predictive likelihood. International Journal of Forecasting, 20(4), 629-645.

Grek, A. (2014) "Forecasting accuracy for ARCH models and GARCH(1,1) family which model does best capture the volatility of the Swedish stock market"? Statistics Advance Level Theses 15hp; Örebro University.

Hall, P., and P., Yao, (2003). "Inference in ARCH and GARCH Models with Heavy-Tailed Errors”, Econometrica, 71, 285-317.

Hsieh, K. C. \& Ritchken, P. (2005) “An Empirical Comparison of GARCH Option Pricing Models". Review of Derivatives Research, 8 (3): 129 -150.

International Peace Institute (IPI)(2009): Underdevelopment, resource scarcity and Environmental Degradation. Task Forces on Strengthening Multilateral Security Capacity. IPI Blue Papers No. 1.

Jarrett, U.; Mohaddes, K. and Mohtadi, H.(2017): Oil Price Volatility, Financial Institutions and Economic Growth. Paper Presented at the $23^{\text {rd }}$ Annual Conference of the Economic Research Forum, Jordan, March 2017.

Jiang, W. (2012) "Using the GARCH model to analyse and predict the different stock markets" Master Thesis in Statistics, Department of Statistics, Uppsala University Sweden.

Kononovicius, A. \& Ruseckas, J. (2015) "Nonlinear GARCH Model and 1/f noise". ARXIV:1412.6244V2[Q-FIN.ST]. 
Lanne, M. \& Saikkonen, P. (2005) "Nonlinear GARCH Models for Highly Persistent Volatility". Econometrics Journal, 8 (2): 251-276.

Malecka, M. (2014) "GARCH Class Models Performance in Context of High Market Volatility”. ACTA Universitatis Lodziensis Folia Oeconmica, 3: 253 -266

Maxwell, J. W. and Reuvey, R.(2000): Resorce Scarcity and Conflict in Developing Countries. Journal of Peace Research, 37(3):301-322.

Mikosch, T. \& Starica, C. (2000) "Limit theory for the sample autocorrelations and extremes of a GARCH(1,1) process". Annals of Statistics, 28 (5): 1427 - 1451.

Milder, S-A.; Richter, S. and Lauster, G.(ed)(2011): Resource Scarcity-A Global Security Threat? SWP Research Paper RP2.

Nelson, D., (1991). Conditional heteroskedasticity in asset pricing: A new approach. Econometrica 59, 347-370.

Nieppola, O.(2009): Backtesting Value-at-Risk Models. M.Sc. Thesis, Helsinki School of Economics, Finland.

Odupitan, E.(2017): Effects of Crashing Crude Oil Prices on Oil Producing Countries: Nigerian Perspective. PhD Thesis, Central University of Applied Sciences, Finland.

Ogiri, I. H.; Amadi, S. N.; Uddin, M. M. and Dubon, P.(2013): Oil Price and Stock Market Performance in Nigeria. An Empirical Analysis. American Journal of Social and Management Sciences, 4(1):20-41.

Okere, K. and Ndubuisi, P.(2017): The Role of Stock Market Development on Economic Growth in OPEC countries: Does Oil Price Movement Matter? Fresh Evidence from Nigeria. Asian Journal of Economic Modelling, 5(2):194-207.

Okoye, P. U.; Mbakwe, C. C. and Igbo, E. N.(2018): Modeling the construction sector and oil prices toward the Growth of the Nigerian Economy: An Econometric Approach. Economies, 6(16):1-19.

Panait, I. and Slavescu, E. O.(2012): Using GARCH-in-Mean Model to Investigate Volatility and Persistence at Different Frequencies for Bucharest Stock Exchange During 1997 -2012. Theoretical and Applied Economics, XIX(5):55-76.

Peterson, B. G.; Carl, P.; Boudt, K.; Bennett, R.; Ulrich, J; Zivot, E.; Cornilly, D.; Hung, E.; Lestel, M.; Balkissoon, K. and Wuertz, D.(2018): Package 'PerformanceAnalytics'. R Team Cooperation

Rossi, E. (2004) "Lecture notes on GARCH models". University of Pavia, March. 
Tsay, R. S. (2005) Analysis of financial time series, 2nd Edition. New Jersey: John Wiley \& Sons.

Ulusoy, V. and Ozdurak, C.(2018): The Impact of Oil Price Volatility and Gas Company Stock Returns and Emerging Economies. International Journal of Energy and Policy, 8(1),144 $-158$

van den Goorbergh, R. and Vlaar, P. (1999): Value-at-Risk Analysis of Stock Returns, Historical Simulation, Variance techniques or Tail Index Estimation? https://www.researchgate.net/publication/4810065. downloaded on 19-11-2018.

Xekalaki, E. and Degiannakis, S.(2010): ARCH Models for Financial Applications. Great Britain: John Wiley \& Sons Ltd. 